\title{
Washington State One Health Initiative: A Model Framework to Put One Health in Action
}

\author{
Wayne Clifford* \\ Washington State Department of Health, Tumwater, WA, USA
}

\section{Objective}

This presentation describes a model of the process used to form Washington State's One Health Initiative. We will provide three examples of how the One Health model is being applied to three emerging pathogen issues. Our objective for this information is to provide this model for others to consider who may be seeking to establish One Health Initiatives in their own regions.

\section{Introduction}

Motivated by the global One Health movement, the Washington State Department of Health began a strategic effort to form a One Health Initiative for the state in early 2014. Early research on the topic found that many states were working on One Health, but we did not find any published models of the processes used to establish it as an initiative.

\section{Methods}

The process that we developed has seven basic components:

- Authorizing Environment. The initiative was authorized and supported by senior leadership.

- Conceptualization. The development team researched, and conceptualized what One Health would look like for Washington State.

- Narrowing Scope. Initial brainstorming resulted in an overwhelming scope that was narrowed down to a manageable size. Our structure started with a strategic level steering committee.

- Personalization. We met individually with senior leadership from each organization that we thought should be on the steering committee to gain buy-in.

- Visioning. We used an interview tool to help the steering committee create their vision and mission.

- Committee Charter. We developed a committee charter that provided the framework for how the committee would do its work.

- Meetings. The committee held in-person meetings and worked together to identify issues.

- Issue Prioritization. The committee members engaged in a process that focused on identifying the highest priority issues. The committee selected antimicrobial resistance/stewardship, and One Health surveillance and data systems as the two top priorities.

- Implementation. The committee now has a three year action agenda with two workgroups focused on prioritiy issues. Two workgroups were formed to focus on antimicrobial data and stewardship, and One Health surveillance data. That work is ongoing.

\section{Results}

The results of this effort include:

- Formation of Washington State's One Health Steering Committee. The committee has a strategic focus that provides guidance and direction.

- Formation of Two Workgroups. Out of the strategic dircetion of the steering committee, we formed two tactical workgroups: the Antimicrobial Stewardship Workgroup, and the Surveillance and Data Systems Workgroup.

- Increased Ineternal Collaboration. Within the Department of Health, human Communicble Disease Epidemiology and
Environmental Public Health Sciences are separated organizationally in different divisions, and geographically by 75 miles of congested freeway. Our internal focus on increased collaboration has helped us bring the two divisions closer together.

- Increased External Collaboration. Agencies, academic institutions, and organizations are working closer together on projects.

- Application of the Model to Other One Health Issues. Awareness of the One Health model has increased within the agency resulting in an interest in applying the model to other health issues.

\section{Conclusions}

1) The cornerstone to One Health is Collaboration. Collaboration is a time investment. Project managers need to build that time in to projects to make collaboration effective.

2) Healthy leadership is critical to forming and maintaining relationships.Conflicts occur, and success depends on staying focused on constructive outcomes.

3) As collaboration increases, so do the needs that are being served. Collaborators need to be transparent with the team about what their needs are from the project.

\section{Keywords}

Health; Zoonotic; Collaboration

\section{Acknowledgments}

Dr. Ron Wohrle, Washington State Department of Health Maryanne Guichard, Washington State Department of Health

Dr. Terry McElwain, Washington State University

Dr. Kathy Lofy, Washington State Department of Health

Dr. Peter Rabinowitz, University of Washington

Dr. Kristin Mansfield, Washington State Department of Fish and Wildlife

Dr. Joe Baker, Washington State Department of Agriculture

Candace Joy, Washington State Veterinary Medical Association

Dr. Paul Pottinger,University of Washington

Robert Duff, Office of the Governor

Dr. Gordon Plotts, Kulshan Veterinary Hospital

Dr. Marisa D'Angeli, Washington State Department of Health

Hanna Oltean, Washington State Department of Health

Melissa Kemperman, Washington State Department of Health

One Health Workgroup Members

\section{*Wayne Clifford}

E-mail: wayne.clifford@doh.wa.gov 